The earthquake is being investigated by Dr. Mario Baratta on behalf of the Italian Geographical Society. A preliminary notice by Dr. G. Martinelli will appear in the next nuniber of the Bollettino of the Italian Seismological Society, and will include the map of the isoseismal lines reproduced here, and also a map prepared by Dr. Baratta to illustrate the seismic history of the district. From the latter, it is evident that the epicentral area of the recent earthquake, though not far distant from the imporfant seismic zone of Aquila, is one in which only earthquakes of slight intensity have originated in the past.

Since the above was written, a short paper on the earthquake by Dr. G. Agamennone has appeared in the Rendiconti of the R. Accad. dei Lincei (vol. xxiv., 1915, pp. 239-46). The author states that the most sensitive microseismometrograph at Rocca di Papa (about forty-three miles from the epicentre) recorded 240 after-shocks from 8.37 a.m. to midnight (that is, from 7.37 a.m. to II p.m., G.M.T.) on January I3, and on $\epsilon$ ach of the four succeeding days $120,88,38$, and 30 , the total number of after-shocks until February 6 being nearly 750, of which only about thirty were felt at the observatory or in the surrounding country.) Charles Davison.

\section{SANITATION IN INDIA. ${ }^{1}$}

$\mathrm{W}^{\mathrm{B}}$ have before us four volumes of papers presented to the All-India Sanitary Conference held at Lucknow in January of last year. Vol. ii. commences with an interesting account of the methods by which in Italy the silt of rivers is utilised for raising the level of the soil, while at the same time the level of the water is lowered by drainage. The system can be carried out with the primary object in view of reclaiming swampy land or the agricultural improvement can also be considered, an almost necessary procedure from the financial side. How far the method is applicable to India is a matter of great interest. One factor that has to be determined is the amount of silt in the particular river under consideration, and, secondly, if agricultural improvement is to be considered, whether the silt is of manurial value. The views of the agriculturist, the engineer, and the sanitarian all need consideration in a problem of this magnitude. How manifold and fundamental the problems are, a consideration of the papers dealing with malaria will show. It is indeed no little achievement that this immense malaria problem is now being studied in India in all its aspects, and that its solution has already progressed far from the facile position held not so long ago by many that the filling up of a few pools and ditches was the answer.

An anti-fly campaign was carried out in Delhi with considerable success, the methods employed being :(I) Either the burning of rubbish or covering it with one foot of earth; (2) the trenches of trenching grounds were cut $I \frac{1}{2} \mathrm{ft}$. deep and covered with a foot of earth well-rammed down; (3) the use of incineration at the latrines; $(4)$ the cleaning and sprinkling with pesterine of stables, cowsheds, backyards, etc.; (5) litter was removed daily or burned, bedding was changed at least once a week; (6) garden manure was not allowed to be exposed for more than four days-after this it must be dug into the ground and covered with a foot of earth; (7) butchers' shops and vegetable shops were dealt with; and (8) in private latrines, pucca floors and drains were made compulsory. The result of this campaign was that flies were "enormously reduced" and apparently the infantile mortality statistics. It

1 Supplement to the Indian Journal of Medical Research. Proceedings Igr. 19r4. Vol. ii., Papers, pp. ii+186. Vol. iii., Papers, pp. iv+220. Vol. iv. Spink and Co., rgr4.)

$$
\text { NO. } 2368 \text {, VOL. 95] }
$$

was not, however, until the breeding-grounds within the city-i.e. those comprised under headings (4) to (8) -were dealt with that progress was made.

In England the essential points in the bionomics of the fly have been known for some years, but flies still infest our large towns. Is it the inadequacy of the powers possessed by the sanitary authorities that allows this insane condition to continue, or is it the apathy that allows us also almost without a murmur to permit foul smoke to be discharged from our chimneys?

The section on conservancy contains. two interesting notes on the "pitting" of night soil, a simple and effective method of solving under certain conditions this ever-recurring problem. The essence of the method consists in sealing the pits from access of flies, etc., with road sweepings.

In vol. iii., the problems of tuberculosis and the very difficult one of a pure milk supply, water supply, notification of disease, and various questions in connection with sewage disposal, are discussed in several papers. An important one is the disposal of sewage sludge; the Grossman process in use in Oldham, where the sludge is dried and freed of its fat by passing steam through, yielding a valuable manure, seems successfully to solve the problem under certain conditions.

Vol. iv. The regulations for the control of malaria in Portuguese India are somewhat rigorous, e.g. all vessels intended to hold water will be closed and their contents changed at least every two days. Once a week at most is sufficient, as mosquitoes cannot develop from eggs in two days. Again, not only are ventilation outlets of drains to be furnished with wire gauze, but oil is to be poured into the openings to make assurance doubly sure, we suppose. A method for destroying larvæ that we do not remember to have seen mentioned before is contained in the following regulation. "Herds of animals will be introduced periodically (into ponds) to stir up the water, thus making it unsuitable for anopheline larvæ"!

In another paper figures are given which suggest that one species of malaria parasite prevails at one season of the year, another at another. If this is really so, and apparently similar results have been observed elsewhere, it would be important to know the reason for this.

A very interesting paper is that dealing with certain features of malaria in the island of Salsette. One main fact comes out, viz., that malaria increases as one approaches the hills. The study of the conditions in an island have always appeared to us especially interesting, and it is to be hoped that it can be repeated year after year. It shows clearly the great importance of an extended malaria survey of a district before houses are built anywhere and everywhere without consulting expert sanitary opinion.

Another interesting point is the effect of sea breezes in reducing the endemic index of malaria; "villages exposed to the sea-breezes have no spleen rate at all." Emphasis is also laid on that ubiquitous evil, the "borrow" pits along the railway track. Under existing conditions the only practical policy recommended is the abolition of these pits, the exposure of villages to sea breezes by the cutting down of grass and undergrowth, the institution of travelling dispensaries, and the proper control of new building schemes. A general attack on breeding-grounds in rural districts seems impossible. Certain areas of the island are free from malaria, and development should be recommended in these. The question of rice fields and malaria is one of first-rate importance. It would appear that we can get in a rice cultivation area three conditions :-( $x$ ) Healthy: spleen rate, 4.3 per cent.; (2) malaria endemic: 24.1 per cent.; (3) malaria hyperendemic: 
70.5 per cent. The healthy areas are in the open plains, the hyperendemic areas at the foot of the mountains, where shade produced by forest, jungle, long grass, scrub, etc., exists, and (3) the. endemic area with intermediate conditions. These data illustrate also the great value of malaria surveys before recommendations based simply on general principles are carried out.

Guinea-worm prevails to the extent of as much as 4 per cent. in some of the Indian jails. In a certain Bombay village over a third of the Cyclops in the village well contained larvæ, but the villagers put all the usual obstacles in the way of improving the well and their health.

Vol. v. contains an extremely interesting method of classification of Anophelines based on the distribution of "spots" on the wings; three main groups, Protoanopheles, Deuteroanopheles, and Neoanopheles, are easily separated.

The problem of the mode of dissemination of kalaazar is still sub judice; the balance of opinion favours the bed-bug as the agent. It has occurred to the writer as a not impossible hypothesis that perhaps this and some other diseases are not insect-man-insect diseases, but insect-man diseases only, i.e. the infecting agent is inoculated into man from and by an insect, produces its ill-effects, but is not further transmissible.

As regards the destruction of rats in plague prophylaxis, we have the merits of two methods put forward, viz. : ( $\mathrm{I}$ ) phosphorus, made up in attractive balls containing less than 3 per cent., and (2) hydrocyanic acid gas. This last kills not only rats but fleas, and its only drawback appears to be its very poisonous character. Its detection, however, is an easy matter, viz., by means of a paste which forms with it prussianblue. The amount requisite is $\frac{1}{2}-\frac{3}{4}$ of an ounce of potassium cyanide per Ioo cu. ft. It has many advantages over the sulphur dioxide or carbon monoxide methods.

There are many other subjects, such as vital statistics, water filtration, that we have not alluded to, but one would refer those who wish to obtain a general idea of the scope of these important conferences to the summary contained in the first volume. We ought to end with a word of congratulation on the splendid work that is being done.

J. W. W. S.

\section{ORNITHOLOGICAL NOTES.}

$\mathrm{N}$ the February number of British Birds Miss M. D. Haviland continues her account of ornithological observations made in the delta of the Yenisei, dealing in this instance with the little stint. So fearless during the nesting season were these birds that it was with difficulty they were kept far enough away from the camera to admit of the taking of a satisfactory photograph; and a brooding cock captured by the author in her hands, when released returned to the young. In six out of eight instances the sitting birds were cocks, but whether both sexes take their share in incubation was not ascertained.

The distribution of birds in Ceylon, in relation to recent geological changes in that island, forms the subject of an article by Mr. W. E. Wait in Spolia Zeylanica for December, I9r4. (vol. x., part 36). A large proportion of the resident birds, especially in the Kandyan provinces and the wet zone of the low country, are of a Malabar type; but in the north and north-west there is a nearer affinity with those of the Carnatic. Of the peculiar species, the greater number pertain to the Malabar type of the fauna, and have their headquarters in the wet zone, but there are also a few with a Himalayan or Malay facies, although none of the Carnatic types. As the NO. 2368 , VOL. 95] theories advanced by the author to explain these peculiarities in distribution are confessedly tentative, quotation seems unnecessary.

In the Zoologist for February Miss W. Austen records the appearance of a flock of about thirty longtailed tits in a garden at Maida Hill on October I, I9I4, an occurrence which the editor believes to be altogether unprecedented.

To the January number of the $A u k$, and likewise to Blue-Bird for the same month, Dr. R. W. Shufeldt contributes a note on the last survivor of the American passenger-pigeon, which died in the Cincinnati Zoological Gardens on September I, I9I4, at the age of twenty-nine years. Immediately after death the body, packed in ice, was forwarded to the National Museum at Washington, where the skin was carefully removed for preservation, doubtless in the study series. Before this took place a photograph of the head and neck was taken and coloured with Japanese tints from the specimen; this photograph, after the insertion of an artificial eye, being reproduced in colour in the aforesaid issue of Blue-Bird.

R. L.

\section{NOTES ON GLASS. ${ }^{1}$}

A CERTAIN amount of experimental work on glass-ware of various kinds has been carried out recently at the National Physical Laboratory, and it may be of interest to make known some of the results.

Chemical investigations have for some years been dependent on German glass; the publication of the analyses and of test results may, it is hoped, lead some English firms to produce articles which may replace those of German manufacture.

The first table gives the analyses of some thermometric and chemical glass-ware.

Analyses of Thermometer and Chemical Glass-ware.

\begin{tabular}{|c|c|c|c|c|c|c|c|}
\hline & \multicolumn{2}{|c|}{$\begin{array}{c}\text { Thermometer } \\
\text { Glasses }\end{array}$} & \multicolumn{2}{|c|}{$\begin{array}{l}\text { Schott and } \\
\text { Gen., Jena. }\end{array}$} & \multicolumn{3}{|c|}{ Chemical Glassware } \\
\hline & 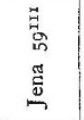 & 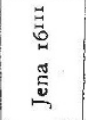 & 苞 & $\begin{array}{l}z \\
z\end{array}$ & 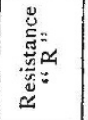 & 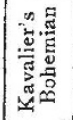 & 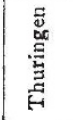 \\
\hline $\begin{array}{lll}\text { Silica } . . & \ldots & \ldots \\
\text { Alumina } & \ldots & \ldots \\
\text { Lime... } & \ldots & \ldots \\
\text { Zinc oxide } & \ldots \\
\text { Manganese oxide } \\
\text { Ferric oxide } & \ldots \\
\text { Lead oxide } & \ldots \\
\text { Soda }\left(\mathrm{Na}_{2} \mathrm{O}\right) & \ldots \\
\text { Potash }\left(\mathrm{K}_{2} \mathrm{O}\right) & \ldots \\
\text { Boric anhydride. } \\
\text { Magnesia ... } \\
\text { Arsenious oxide.. }\end{array}$ & $\begin{array}{c}72 \cdot 86 \\
6 \cdot 24 \\
0.35 \\
\mathrm{tr} . \\
\mathrm{tr} . \\
- \\
9.82 \\
0.10 \\
10.43 \\
0.20 \\
\end{array}$ & $\begin{array}{c}66 \cdot 58 \\
3 \cdot 84 \\
7 \cdot 18 \\
6 \cdot 24 \\
0.28 \\
\operatorname{tr} . \\
- \\
\text { I4.80 } \\
\operatorname{tr} . \\
0.91 \\
0.17 \\
\end{array}$ & $\begin{array}{c}66 \cdot 74 \\
2 \cdot 77 \\
0 \cdot 28 \\
8 \cdot 28 \\
0 \cdot 65 \\
\operatorname{tr} . \\
8 \cdot 99 \\
0 \cdot 08 \\
7 \cdot 18 \\
4 \cdot 50\end{array}$ & $\begin{array}{c}64.60 \\
6 \cdot 24 \\
\operatorname{tr} . \\
10 \cdot 43 \\
\operatorname{tr} . \\
\operatorname{tr} . \\
- \\
9 \cdot 7 \mathrm{I} \\
\operatorname{tr} . \\
8 \cdot 70 \\
0.32\end{array}$ & $\begin{array}{c}68 \cdot 00 \\
2 \cdot 32 \\
4 \cdot 80 \\
2 \cdot 40 \\
0 \cdot 14 \\
\operatorname{tr} . \\
- \\
10 \cdot 17 \\
1 \cdot 82 \\
5 \cdot 53 \\
5 \cdot 04 \\
0.24\end{array}$ & $\begin{array}{l}76.02 \\
0.64 \\
7.38 \\
- \\
\operatorname{tr} . \\
\operatorname{tr} . \\
-7.60 \\
7.70 \\
0.30\end{array}$ & $\begin{array}{l}74.36 \\
0.90 \\
9.40 \\
- \\
\operatorname{tr} . \\
\operatorname{tr} . \\
- \\
14.83 \\
0.14 \\
-16\end{array}$ \\
\hline & $100^{\circ} 00$ & $100^{\circ} 00$ & $99^{\circ} 47$ & $100 \cdot 00$ & 100.46 & $99 \cdot 64$ & $99 \cdot 79$ \\
\hline & * & $*$ & & $*$ & & & \\
\hline
\end{tabular}

Analyses made with an asterisk have been made at the N.P.L. The other analyses are taken from a paper by Walker in the Journal Am. Chem. Soc., xxvii., 865, 1905 .

(Bohemian and Thüringen glass is now rarely used in chemical work, but the analyses given are of the best material of that class.)

Resistance of Various Chemical Glass-ware to the Action of Chemical Attack.

The table below, taken from the work of Mylius and Foerster on this subject, gives the action of

1 From the Na'ional Physical Laboratory, February, Igr5. 